\title{
ARTISTA ARCHIVISTICA, ESCRITORA INVESTIGADORA. LA INTERVENCIÓN DE MARIA MORENO EN LAS OPERACIONES DE LECTURA Y ESCRITURA DE ORACIÓN
}

\author{
ARTISTA ARQUIVISTA, ESCRITORA PESQUISADORA. A INTERVENÇÃO DE MARIA \\ MORENO NAS OPERAÇÕES DE LEITURA E ESCRITA DE ORACIÓN
}

Anabel Tellechea ${ }^{1}$

\begin{abstract}
RESUMEN: María Moreno desarrolla en Oración. Carta a Vicki y otras elegías políticas (2018) una investigación y análisis sobre un tipo particular de subjetividad: aquella atravesada por la identidad militante, en la que se conjugan tanto los modos de asumir la femineidad/masculinidad como el compromiso político y la acción. Emerge, de este modo, la figura del escritor como investigador (KLEIN, 2019) que aparece como una manifestación particular del fenómeno de las narraciones documentales, textos que exploran diferentes maneras de incorporar materiales de archivo y fuentes bibliográficas. Como narración documental, la investigación que compone Oración propone una lectura crítica de un conjunto de materiales diversos: principalmente, de las dos cartas que Rodolfo Walsh escribe en ocasión de la muerte de su hija, Carta a Vicki y Carta a mis amigos; a su vez, el corpus incluye otro tipo de materiales como testimonios, textos literarios, films, periódicos, notas autobiográficas, bibliografía crítica y teórica. Este trabajo se propone revisar los modos en que los tres aspectos que hacen a la narrativa de no-ficción según Cristoff (2014) (es decir, la confluencia entre elementos autobiográficos, un trabajo con los documentos que no excluye la imaginación y la traza de un narrador que es ante todo lector) configuran un trabajo de escritura e investigación e instauran las condiciones del archivo que compone Moreno como artista archivística (FOSTER, 2019). Para ello, tiene como guía la pregunta de qué es aquello que ha permanecido invisibilizado, reprimido en las dos cartas y que "también archiva aquello cuyo archivo disimula o encripta" (DERRIDA, 1997, p. 73).
\end{abstract}

Palabras clave: Narración documental; no-ficción; políticas de archivo.

RESUMO: Maria Moreno desenvolve em Oración. Carta a Vicki y otras elegias politicas (2018) uma investigação e análise sobre um tipo particular de subjetividade: aquela atravessada pela identidade militante, na qual são combinadas as formas de assumir a feminilidade/masculinidade, bem como o compromisso político e a ação. Dessa forma, emerge a figura do escritor como pesquisador (KLEIN, 2019) que aparece como uma manifestação particular do fenômeno das narrações documentais, textos que exploram diferentes maneiras de incorporar materiais de arquivo e fontes bibliográficas. Como narração documental, a pesquisa realizada por Oración propõe uma leitura crítica de um conjunto de diversos materiais: principalmente, das duas cartas que Rodolfo Walsh escreve por ocasião da morte de sua filha, Carta a Vicki e Carta aos meus amigos; por sua vez, o corpus inclui outros tipos de materiais, como testemunhos, textos literários, filmes, jornais, notas autobiográficas, bibliografia crítica e teórica. Este trabalho tem como objetivo revisar as maneiras pelas quais os três aspectos que compõem a narrativa de não ficção segundo Cristoff (2014) (ou seja, a confluência entre elementos autobiográficos,

\footnotetext{
${ }^{1}$ Profesora en Letras por la Universidad Nacional del Sur. Ayudante en la cátedra de Teoría y Crítica Literaria 1 del Departamento de Humanidades (UNS). Doctoranda del Doctorado en Literatura y Estudios Críticos de la Universidad Nacional de Rosario.
} 
um trabalho com documentos que não excluem a imaginação e o traço de um narrador que é acima de tudo um leitor) configuram um trabalho de escritura e pesquisa e estabelece as condições do arquivo que Moreno compõe como artista arquivista (FOSTER, 2019). Para fazer isso, é guiado pela pergunta sobre o que é aquilo que permaneceu invisivel, reprimido nas duas cartas e que "também arquiva o que oculta ou criptografa" (DERRIDA, 1997, p. 73).

Palavras-chave: Narração documental; não-ficção; políticas de arquivo.

Si queremos saber lo que el archivo habrá querido decir, no lo sabremos más que en el tiempo por venir. Quizá. No mañana sino en el tiempo por venir, pronto o quizá nunca. (DERRIDA, 1997, p. 44)

El proyecto de escritura de Oración. Carta a Vicki y otras elegías politicas (MORENO, 2018) se extendió en un espectro de más de quince años. Lo sabemos por una pequeña nota en el umbral del libro donde la voz narradora en primera persona también nos advierte, como una declaración de principio, que Oración es el producto de un deslizamiento: en lugar de escribir sobre la moral sexual en las organizaciones revolucionarias de los años setenta en Argentina, tema con el que ganó la Beca Guggenheim en 2002, María Moreno afirma sin más "escribí este" (2018, p. 9). Me interesa reparar en este gesto, para empezar, por dos cuestiones. La primera se refiere a la prolongada reflexión sobre los materiales reunidos, que da la idea de una rumiación de aquello que se piensa, y que a su vez se expresa en la forma recursiva y no lineal de abordar los documentos expresada en el deseo de "(Q)ue la repetición, la densidad, el avance penoso fueran para la lectura, como lo fue para la escritura, una de las maneras de la oración” (2018, p. 28). La segunda alude a que es tan cierto que Oración no es exactamente un texto sobre la moral sexual de izquierda, como también que definitivamente es una de las líneas que hace converger la heterogeneidad de los materiales que reúne. El deslizamiento, de esta manera, se delinea aquí como una operación de lectura y escritura.

La lectura crítica de Moreno se desarrolla en el marco de una investigación y análisis sobre aquellos sujetos atravesados por la identidad militante, en la que se conjugan tanto los modos de asumir la femineidad/masculinidad como el compromiso político y la acción. Como afirma Paula Klein (2019), la figura del escritor como investigador aparece como una manifestación particular del fenómeno de las narraciones documentales, textos que exploran diferentes maneras de incorporar materiales de archivo y fuentes bibliográficas. Como tales, proponen un trabajo con los documentos a partir de una modalidad que se desprende del modelo de la investigación histórica y archivística para proponer otras; al hacerlo, tensionan los límites entre lo literario y la investigación social. Para delimitar la categoría de narraciones documentales, Klein sigue los planteos de "Un réalisme contemporain: les narrations documentaires", de Lionel Ruffel, quien sostiene que "se trata de obras que pertenecen a tradiciones heterogéneas: crónicas y relatos de viaje, investigación sociológica, ensayo político, relatos biográficos y autobiográficos, relatos etnográficos, gran reportaje y non-fiction o nuevo periodismo" (RUFFEL, cit. en KLEIN, 2019, p. 6).

Como toda investigación, Oración es un texto en el que Moreno necesariamente articula una hipótesis, pero lo hace en el sentido que afirma Cristoff (2014) cuando ensaya su definición de narrativa de no-ficción, la tradición en la que anida esta narrativa documental. En el modo 
de escribir (y no tanto de ser leídas), estas narrativas delimitan una hipótesis y muestran "las estrategias a partir de las cuales está construida, el trabajo sobre el terreno en el que se apoya, las lecturas con las que dialoga, las posturas con las que discute" $(2014$, p. 15). Si bien la hipótesis de Oración nunca se explicita como tal, podría sintetizarse como la afirmación de que es posible encontrar, en un documento representativo de los emblemas del compromiso militante, elementos que fisuran ese sistema de valores e instalan las posibilidades de un lugar individual de subjetivación para una mujer. Es en este sentido que, entre otros posibles, Oración es el resultado de la lectura de género que Moreno realiza de las dos cartas que Rodolfo Walsh escribe en ocasión de la muerte de su hija, Carta a Vicki y Carta a mis amigos; específicamente, me refiero al análisis sobre la decisión de Walsh de atribuirle esas últimas palabras — "Ustedes no nos matan, nosotros elegimos morir" (MORENO, 2018, p. 22) - y hacer de esta manera que su muerte sea "gloriosamente suya".

Como narración documental, la investigación tiene por núcleo las dos cartas, incluidas en versión completa al inicio y retomadas en forma fragmentada para su análisis pormenorizado. Además, el corpus incluye otro tipo de materiales como testimonios, textos literarios, films, periódicos, notas autobiográficas, bibliografía crítica y teórica. Estas narrativas se caracterizan por una fuerte voluntad referencial sin afiliarse al realismo, por el contrario, "buscan abrirse a la 'potencia de lo real' importando métodos y procedimientos del periodismo pero también de las ciencias sociales" (KLEIN, 2019, p. 6). Con menos afán clasificatorio que crítico, el modo en que Cristoff entiende la no-ficción permite atender a las maneras en que en Oración confluyen "elementos de la autobiografía, un trabajo con los documentos que no excluye la imaginación y la traza de un narrador que es ante todo lector" (CRISTOFF, 2014, p. 16). Este trabajo se propone revisar los modos en que estos tres aspectos configuran un trabajo de escritura e investigación e instauran las condiciones del archivo que compone Moreno como artista archivística (FOSTER, 2019). Para ello, tiene como guía la pregunta de qué es aquello que ha permanecido invisibilizado, reprimido en las dos cartas y que "también archiva aquello cuyo archivo disimula o encripta" (DERRIDA, 1997, p. 73).

\section{La narración documental como intervención}

En el ya clásico El relato de los hechos (1992), Ana María Amar Sánchez caracterizaba el texto de no-ficción como "una versión que enfrenta otras versiones de los mismos hechos, sólo que trabaja sin omitir testimonios, grabaciones y discursos que las otras silencian" (1992, p. 34). La hipótesis que articula Oración trabaja sobre fuentes documentales cuyo origen pertenece a la esfera privada ${ }^{2}$, ya sean las dos cartas o los testimonios que Moreno obtiene de Patricia Walsh o de la familia Mainer. Todas ellas componen un tejido de versiones sobre los hechos acontecidos en el operativo de la casa del Corro el 29 de septiembre de 1976 que lejos de completarse entre sí, muestran la incongruencia y las contradicciones que emergen del cotejo entre relatos.

Los usos de las cartas de Walsh y de los testimonios ameritan consideraciones críticas específicas para cada uno. En el caso de las primeras, una de las operaciones más destacadas que realiza Moreno en tanto narradora-lectora es la desarticulación del par dicotómico público/privado, perspectiva que la acerca a la literatura como realidadficción (LUDMER,

\footnotetext{
${ }^{2}$ Las obras analizadas (Aparecida o Diario de una princesa montonera, por mencionar algunas) podrían constituir una excepción a este aspecto. No obstante, no considero que formen parte de la formulación de la hipótesis, sino que conforman una zona particular del libro cuyo desarrollo depende de esa hipótesis.
} 
2009). Estas esferas, delimitadas por el pensamiento de la modernidad, pierden especificidad en el análisis de Moreno al enfocar el modo en el que están escritas, más allá del carácter público que cobraría cualquier carta puesta en circulación. Carta a mis amigos es al mismo tiempo "una carta abierta, una necrológica revolucionaria y la despedida privada de un padre" (MORENO, 2018, p. 93), mientras que "Carta a Vicki, leída en pendant con Carta a mis amigos, se convierte, a pesar de haber quedado oculta dentro de papeles privados, en una carta abierta, al igual que las más excelsas piezas del género" (2018, p. 34). La desestabilización de la cualidad de público/privado de las cartas, si bien lo analizaremos más adelante, remite al fin del pensamiento en esferas, que para Ludmer indica "la situación de pérdida de autonomía de "la literatura' (o de 'lo literario')” (LUDMER, 2009, p. 43).

Otro tipo de problemas ofrecen los testimonios que Moreno pone en diálogo con las cartas, dado que se trata de fuentes "extrañas, recuperadas a través de un gesto de conocimiento alternativo o de contra-memoria” (FOSTER, 2019, p. 165). Como artista archivística, Moreno procura "hacer físicamente visible alguna información histórica, frecuentemente perdida o desplazada" (ídem), que en el caso de Oración se trata de la historia contada por las propias mujeres, protagonistas o testigos. Desplazada se considera Patricia Walsh, por ejemplo, cuando en su testimonio cuenta cómo distintas personas aparentemente interesadas en investigar sobre su padre menosprecian, desestiman aquello que tiene para decir precisamente porque no se ajusta al conocimiento hegemónico de la materia:

... pareciera ser que, a pesar de que soy la hija, o ese no es mi padre o yo no lo recuerdo porque hay algo que convence de lo que sería - por llamarla de algún modo- la versión oficial. Entonces, al contar otra, se dañaría esa donde hay un avanzado estado de construcción del personaje. Y a mí casi me han llegado a convencer de que lo que yo quiero aportar es secundario o es molesto. (MORENO, 2018, p. 301)

En esta misma línea, esa 'versión oficial' sobre el personaje Rodolfo Walsh silencia no solo la voz y presencia de su hija sino también la de otras mujeres cercanas a él. En palabras de Patricia, "Mi mamá es una mujer ignorada por las biografías. Y creo que las otras mujeres de mi padre ${ }^{3}$ también, no solo mi mamá.” (MORENO, 298, p. 2018)

Si la María Moreno de la primera persona puede recuperar esta información descartada, negada, se debe en principio a la posición subjetiva que enuncia en el capítulo "Nota al pie", y que se abre con un interrogante personal: "Muchas veces me pregunté por qué no formé parte de ellos" (MORENO, 2018, p. 143), en referencia a las orgas. Este segmento de Oración es el que revela con mayor potencia la traza de esa escritura autobiográfica que Cristoff atribuye a la narrativa de no-ficción. Dicha posición aparece marcada, por un lado, por un distanciamiento relativo: a la vez que reconocía cierta afinidad con la militancia, esta se revelaba como insuficiente para integrarse al grupo, como cuando afirma "había algo en ese 'nosotros' que me tentaba sin decidirme" (2018, p. 145). Por otro lado, se trata de una subjetividad con una capacidad de ver y oír distintiva; como nos lo recuerda Mónica Bernabé (2017) a propósito de su escritura plebeya, "(E)l oído atento de María Moreno ha sido entrenado en la estereofonía de

\footnotetext{
${ }^{3}$ Un año después de Oración se publicó Historia de una investigación (2019), de Enriqueta Muñiz (Editorial Planeta). Allí se recuperan los cuadernos que escribió Muñiz como compañera de investigación de Rodolfo Walsh para el fundacional Operación Masacre. Fuertemente invisibilizada hasta el momento por la crítica, esta voz y presencia prometen una fuerte fisura en el avanzado personaje oficial de Walsh, en la dirección que opera la propia Moreno.
} 
los bares" (2017, pp. 117-118).

Para el ejercicio de esta modalidad perceptiva, el lugar en los márgenes que ocupa la escritora resulta fundamental en tanto le permite mantener una posición externa y a la vez de marcada proximidad. "Cualquiera que, como yo, estuviese fuera del ritmo torrencial de la radicalización podía ver lo que los otros no veían” (MORENO, 2018, p. 150), afirma al recordar una conversación de 1974 con su pareja de entonces, un joven militante. Pero aquello que logra percibir no se limita a una observación para la militancia en general, como cuando recuerda haber calculado, tan terrible como acertadamente, "que les quedaban dos años antes del exterminio" (ídem), sino que capta una problemática mucho más particular (una sintonía más fina) y es la que define con precisión la hipótesis de Oración: la necesidad de ver —aún hoyuna zona invisibilizada, el lugar que ocuparon las mujeres en la lucha armada, sus condiciones y problemáticas subjetivas. La urgencia y la capacidad de preguntarse por el lugar diferencial de las militantes se configura, a su vez, como una oportunidad para indagar su propia posición con respecto a las agrupaciones.

Vemos que dicho lugar diferencial es no solo reconocido sino también ponderado por esas mujeres gracias a esta capacidad auditiva que logra interpelarlas de manera tal que ellas se permitan explorar su individualidad, hasta el momento postergada. "En lo que las ex combatientes explicaban como mi modo de escuchar, decían sentir una invitación a interrogarse por esa dimensión personal que yo había explorado sin poner la vida en riesgo y para la que la revolución no había tenido lo que un texto feminista llamaba palabras para decirlo" ${ }^{\text {(MORENO, }}$ 2018, p. 152). El oído de Moreno, formado en psicoanálisis -teoría que afirma haber abordado "con una vehemencia de afiliada, menos como estudiosa que como grupie adelantada" (2018, p. 146) y que aprendió en las "lecciones de la universidad laica que, en la Argentina de los sesenta y setenta, funcionó en los bares, los grupos de estudio” (BERNABÉ, 2017, p. 118)-, habilita espacios para enunciar una voz y articular un discurso individual divergente de la moral de izquierda, a la vez que es capaz de fisurar la asimilación identitaria cuya máxima es el deseo de "fundirse con los otros". Este acercamiento efectuado por Moreno, por supuesto, no genera ninguna suerte de homogeneización entre las partes. Ella sigue siendo la outsider: "Escucharlas porque eran ellas las que, por sobre todo, me interesaban-, no hacía desaparecer la tensión de una desigualdad perniciosa para el encuentro: la de que yo no hubiera combatido, la de ser (...), amén de una perejila, una analista de los goces" (MORENO, 2018, p. 152). Sin embargo, Moreno ya no es una mera simpatizante que nunca tomó las armas, sino que se convierte en una interlocutora válida para esas mujeres justamente al reivindicar la dimensión subjetiva, es decir, al tensionar (y no 'negar') el supuesto aceptado que funciona como condición de pertenencia colectiva.

Es a partir de este interés, las experiencias de estas mujeres, que Oración constituye una verdadera intervención que trasciende la mera "manifestación de una posición política" (BERNABÉ, 2006; p. 13), ya que realiza "una operación de interpelación ética que actúa e intercede para que se produzca el encuentro entre el lector y aquello que permanece invisible a primera vista o aquello que no vemos — o mejor - que no queremos ver" (ídem). Pero ¿a quién está dirigida esta interpelación? Si bien el fin de la demora, la terminación de este libro se debe a circunstancias en principio personales (me refiero al miedo a la inminencia de la muerte) $)^{5}$,

\footnotetext{
${ }^{4}$ Todos los destacados en las citas seleccionadas pertenecen al original.

5 "Quise escribir. Pensé que, si no lo hacía, no podría ya escribir otra cosa. Tardé, desistí, volví a intentarlo. Dudé. Hasta que la prórroga que me había dado venció: ya tengo edad para morir. Entonces, a los apurones, terminé lo que me había impuesto como una deuda." (MORENO, 2018, p. 28)
} 
también hay otra amenaza que acecha en presente y en forma apremiante:

Hoy, el Estado forajido, en lugar de dar sus pruebas ante los delitos de los que se lo hace responsable, es el que exige a las víctimas pruebas y evidencias, levantándoles prontuario, violando sus intimidades y, en un nuevo negacionismo, redondeando para abajo la contabilidad del terror, volviendo urgente la política del número walshiana, para una contabilidad de justicia, donde Bartleby preferiría hacerlo. (2018, p. 366)

Así como en otro lugar de Oración declara explícitamente la necesidad de la distinción entre 'exacto' y 'justo', de la que fue maestro Walsh y que supone una política del número donde "el número justo siempre agrega", este retorno del negacionismo por parte del Estado no es el único objeto de llamado de atención hacia aquello que no se quiere ver. Lo que resulta profundamente incómodo, y por ello constituye en verdad una intervención ética y política, es la interpelación al "canon de los derechos humanos" (MORENO, 2018, p. 259) que ha hecho caso omiso a las circunstancias y vivencias específicas de las mujeres. Moreno en tanto archivista salva $^{6}$ los testimonios dispersos de estas "figuras silenciadas" (2018, p. 260), enmudecidas, y opera "uno de los mayores y más necesarios gestos de una comprensión desconstruccionista de la historia” (DERRIDA, cit. en GERBAUDO, 2016, p. 41): la exhumación de las voces "reprimidas, desvalorizadas, minusvaloradas y ocultas por los cánones hegemónicos" (ídem).

Si esta perspectiva hegemónica pasó de ser bien intencionada a biempensante, si resultó arrasadora en la imposición de sentidos válidos para los modos de interpretación y vivencia del horror de las mujeres durante - y después de - la última dictadura militar, lo fue por coartar las posibilidades del agenciamiento del deseo. Aquellas mujeres víctimas de la violencia del terrorismo de Estado también fueron "(V)íctimas del menosprecio bajo el peso de la figura sagrada de las Madres porque habían cogido y podían volver a hacerlo" (MORENO, 2018, p. 260). Moreno interviene, por lo tanto, para recuperar esta dimensión soslayada, para resolver esas preguntas que en los setenta representaban los miramientos con los que no terminaba de convencerse para comenzar a militar, como cuando se preguntaba "¿y las mujeres?, ¿y el deseo?" (2018, p. 146).

Es acá donde Oración está más cerca de aquel proyecto inicial y a la vez exhibe el deslizamiento que señalábamos al principio: Moreno analiza la moral sexual no solamente de las organizaciones revolucionarias de los años setenta, sino también de aquellos y aquellas que buscando justicia para sus muertos también ejercieron violencia sobre las sobrevivientes por efecto de su apego a las ideas tradicionales en torno al rol de las mujeres en las familias. El núcleo de la disputa de sentido se ubica aquí, en el reclamo por una perspectiva que no fue reconocida en la instauración del archivo, instancia en la que "(E)l primer archivero instituye el archivo como debe ser, es decir, no sólo exhibiendo el documento, sino estableciéndolo. Lo lee, lo interpreta, lo clasifica" (DERRIDA, 1997, p. 63). Moreno señala que en el establecimiento de sentidos, las "Madres como santas madres se impusieron sobre las muchachas que poseían los secretos de esos cuerpos inmolados: los de su goce" (2018, p. 259). Desde esta perspectiva las mujeres "no solo encarnaban un duelo de segunda sino que esos derechos humanos enunciados

\footnotetext{
${ }^{6}$ En Mal de archivo, Derrida se pregunta cuál es el momento propio de la archivación, stricto sensu, si es que hay uno. Para ello, revisa tres posibles sentidos del concepto de 'impresión', y entre ellas, se refiere al de '"salvar' (save) un texto indemne, de modo duro y duradero, para poner unas marcas al abrigo de la borradura, con el fin de asegurar así salvación e indemnidad, de almacenar, de acumular y, lo que es a la vez la misma cosa y otra distinta, de tornar así la frase disponible para la impresión y la reimpresión, para la reproducción” (DERRIDA, 1997, p. 34).
} 
por cuerpos sexuados, con relación a los de las víctimas [fatales], portaban (...) todo lo que los hombres y las mujeres eran más allá de sus deberes" (2018, p. 260). Moreno logra exponer la intromisión del conservadurismo, en este caso con respecto a los mandatos de género, nada más ni nada menos que en la agrupación quizá más emblemática del progresismo local, y al hacerlo nos recuerda que el mal de archivo (DERRIDA, 1997) está ligado indefectiblemente a una "decisión destinada a hacer sobrevivir ciertos materiales en menoscabo de otros" (GERBAUDO, 2016, p. 37), ya se trate "de todos los revisionismos detestables como de las más legítimas, necesarias y valientes reescrituras de la historia” (DERRIDA, 1997, p. 97). En síntesis, el efecto que persigue Oración está lejos de deslegitimar el reclamo de las Madres, sino que propone una tercera vía: al mismo tiempo que impugna el negacionismo, demuestra que es igual de necesario disputar los sentidos del canon para que el reclamo sea verdaderamente justo, sin duelos ni víctimas 'de segunda'?

\section{La ficción como articulación de materiales}

Ya hemos referido que Oración reúne materiales de diversa índole y procedencia. Para precisar un poco más esta idea, en el contexto de la no-ficción según la entendemos en esta lectura, observamos que dicha reunión supone un montaje de documentos en el que, por un lado y aunque resulte una obviedad, no se valoran jerárquicamente unos sobre otros según los criterios de la investigación académica. Por el contrario, Moreno en tanto archivista compone un tejido en el que realiza una serie de operaciones — seleccionar, organizar y recortar los documentos- que van "siguiendo y a la vez conformando los pasos de su propia hipótesis" (CRISTOFF, 2014, p. 19). Por otro lado, y como consecuencia de que lo que hay en Oración es un uso de los materiales que reúne más que una mera incorporación, estos documentos cuestionan el "positivismo de la prueba" en la misma línea que lo hace el propio Walsh. Lejos de entenderlos como "reflejos de la realidad', como suele decirse, ni tampoco [como] fuentes de información y/o ilustración” (2014, p. 18), aquello que se reivindica es, precisamente, la escritura como una construcción ficcional. Moreno sigue a Philippe Mesnard cuando propone deslindar dos términos que se desprenden de 'ficción': lo ficticio es aquello que "se aparta de la verdad y enmascara", mientras que lo ficcional "usa procedimientos y dispositivos que permiten hacer surgir la dimensión documental de los testimonios” (MORENO, 2018, p. 366). Esa dimensión documental gana en potencia al mismo tiempo que exactitud y justo dejan de ser términos intercambiables. Si lo decimos con las palabras de la escritora, en síntesis, "la ficción es de un orden diferente a la mentira" (2018, p. 93).

El adelantamiento de Walsh a Capote, para Moreno, es uno de los "mitos" que abonan la versión oficial de su figura de autor. Justamente ahí elige operar otro deslizamiento: sin negar que efectivamente Operación Masacre es cronológicamente anterior a A sangre fría en lo que respecta a no-ficción, elige colocar la producción de Walsh en otra tradición: junto a Facundo de Sarmiento y Una excursión a los indios ranqueles de Mansilla, libros tutores de la literatura nacional. La operación implica arrojar la producción de Walsh a un estadio de la literatura anterior a las condiciones de autonomía bajo la hipótesis de que "Lo que Walsh deseaba no era trabajar en la tensión entre ficción y realidad, entre hechos narrados con las prerrogativas de la ficción, o sobre ficciones referidas a materiales reales, o híbridos perfectos que operaran de

\footnotetext{
7 "Paradójicamente solían ser consideradas mujer de, sin que esto determinara un territorio de reclamo específico sino de segunda, convirtiendo su rol en un acompañamiento de la militancia, aunque muchas de ellas hubieran tenido rangos mayores que sus compañeros" (MORENO, 2018, p. 259).
} 
diversos modos" (2018, p. 92). Por más inagotable que resulte la discusión de qué es la literatura y cuáles son las condiciones que le impondría su autonomía, el enfoque de los problemas planteados por Ludmer en torno a las literaturas post-autónomas puede ser verdaderamente operativo para considerar las operaciones de lectura de Moreno a los fines de entender los modos en que Oración transita la inespecificidad de lo literario. Me refiero especialmente al concepto de escrituras diaspóricas, que no "solo atraviesan la frontera de 'la literatura' sino también la de 'la ficción' (y quedan afuera-adentro en las dos fronteras)” (LUDMER, 2009, p. 42). Esa situación de indefinición, la incapacidad de definir en qué lugar se sitúa la escritura, hace que la propia noción de 'frontera' se vuelva inoperante, y en este punto es que Moreno hace hincapié: cuando afirma que el deseo de Walsh era producir "textos que fueran capaces de liquidar esas cuestiones de fronteras" (2018, p. 92), logra adelantarlo no solo a Capote, sino también a los problemas de la post-autonomía.

\section{Pensar con Walsh}

Para ensayar el papel de criptóloga, Moreno hace una puesta en escena y declara: "Voy a hacer una performance y cometer una impertinencia: colocarme en el lugar de Walsh frente a la doble página La Opinión del 2 de octubre de 1976" (MORENO, 2018, p. 114). Sin perder de vista que se trata de un episodio muy puntual, me interesa revisar los alcances de ese como si. Rosi Bradotti (2000) propone una figuración del sujeto feminista como sujeto nómade, y lo define como una "metáfora performativa que permite que surjan encuentros y fuentes de interacción de experiencia y conocimiento insospechadas que, de otro modo, difícilmente tendrían lugar." (2000, p. 32). Uno de los modos de efectuar esa performance es, justamente, la práctica política del como si, cuya efectividad no reside en "la personificación mimética o la capacidad de repetir poses dominantes sino antes bien [en] la medida en que estas prácticas abren espacios intermedios en los cuales es posible explorar nuevas formas de subjetividad política." (BRAIDOTTI, 2000, p. 35)

La performance de Moreno, considerada desde este punto de vista, nos abre una serie de preguntas. ¿Acaso este posicionamiento se limita a la obtención de las conclusiones que extrae del análisis del diario? La experimentación de esa lógica, es decir, sentarse a pensar como él, ¿no podría extenderse a un campo más general, el de las consideraciones que Moreno lee y releva detalladamente acerca de la concepción de escritura de Walsh? Recordemos que el proyecto literario del escritor, según se afirma en Oración, giró en torno a la búsqueda de una forma que lograra "intervenir en lo real modificándolo" (2018, p. 92) y para ello, la escritura se concebía "como un acto, al darle la capacidad de transformar las condiciones de aquello que denunciaba" (ídem). Este tópico se convierte en un hilo conductor que va tejiendo diferentes partes del libro y que tiene como efecto la puesta en abismo de Oración en una caja de resonancia donde se piensan las posibilidades de este tipo de escrituras.

Cuando Moreno integra en su collage fragmentos del reportaje que realiza Ricardo Piglia al propio Walsh sobre la desavenencia de conjugar denuncias con la forma de la novela burguesa $^{8}$, es posible leer allí un segmento en el que el texto se vuelve autorreflexivo; un

\footnotetext{
8 “... la noción de que una novela con ese tema es mejor o es una categoría superior a la de una denuncia con ese tema. Yo creo que esa es una concepción típicamente burguesa, de la burguesía y ¿por qué? Porque evidentemente la denuncia traducida al arte de la novela se vuelve inofensiva, no molesta para nada, es decir, se sacraliza como arte." (WALSH, cit. en MORENO, 2018, p. 331)
} 
microensayo sobre la búsqueda de la forma con la cual escribir la investigación en cuanto noficción (cuyo resultado, en el caso de Moreno, es la narración documental que compone Oración). En ese reportaje, Walsh postula la esperanza o la pretensión de que en un futuro la forma del testimonio, de la denuncia o del documento sea apreciada en cuanto a arte dado que su elaboración, "como todo el mundo sabe, admite cualquier grado de perfección. Es decir, evidentemente en el montaje, en la compaginación, en la selección, en el trabajo de investigación se abren inmensas posibilidades artísticas" (MORENO, 2018, p. 344-345). Además de la figura de escritor de no-ficción, las declaraciones en esta entrevista sugieren un Walsh artista archivístico con el cual Moreno, más que identificarse, entabla un diálogo, y es por esto que aquello que la autora sintetiza como "el arte [...] de elegir, montar y compaginar en el interior de una investigación” (2018, p. 332), parafraseando al cronista, también resuena para su propio proyecto.

Si la ficción es de un orden diferente a la mentira, si ambos escritores liman el par dicotómico verdadero/falso, lo que emerge es en definitiva otra forma de conocimiento, de obtener algún tipo de verdad (y no la verdad). Afirma Amar Sánchez con respecto a la no-ficción que es "indudable que uno de los rasgos fundamentales del género es su búsqueda de la verdad de los hechos: los textos investigan y trabajan con las evidencias, las pruebas, los testimonios comprobables." (AMAR SÁNCHEZ, 1992, p. 34). Pero la verdad de los hechos "es la que surge de esos testimonios, de su montaje, y no está en una realidad de la que se puede dar cuenta fielmente, sino que es el resultado de la construcción" (ídem), del trabajo de escritura. Moreno en tanto escritora-investigadora se propone exhibir las contradicciones entre los testimonios que compagina, y como lectora va a buscarlas en las Cartas. ¿Para corregir a Walsh? Muy por el contrario, para darle aún más potencia a los textos, porque "son los testimonios coherentes, sin agujeros en la memoria, acoplables entre sí en una consistencia deliberada, los que menos iluminan lo acontecido" (2018, p. 289). En las cartas, además de la pregunta sobre a quién atribuir aquellas palabras finales, dado que sobrados indicios sugieren que no fue Vicki quien las pronunció, también Moreno observa una incongruencia de la que brota "la verdad del texto" (2018, p. 375): "El hombre del dato y de la evidencia sabe que no amanece a las nueve de la mañana, hora del comienzo del ataque a la casa de la calle Corro. Pero no se equivoca: adelanta la hora" (2018, p. 374). Si fuera posible encontrar alguna verdad sobre estos hechos traumáticos, será en los puntos divergentes, y es por esto que el deslizamiento (y no la refutación) se presenta como una operación de lectura y escritura fundamental en Oración. En definitiva, no es un error, es ficción.

Moreno introduce otra manera de leer las cartas: propone considerarlas como un par que se retroalimenta; concluye que los dos documentos le desestabilizan uno al otro su carácter de público/privado; y abona la lectura de Link en la que Carta a Vicki, al tener uno y no dos puntos después del encabezado "Querida Vicki", no pertenece al género epistolar (cfr. MORENO, 2018, p. 338). Además opera una torsión en la versión oficial del personaje de Walsh. La figura del escritor comprometido, tensionado entre las letras y las armas, se complejiza con otra que Moreno encuentra también en sus propios textos: de las cartas emerge otro Walsh en el que existen una dimensión que se ocupa del deseo y una preocupación por el lugar individual de la hija militante, Victoria. Y ahí es donde Moreno, en este juego de ponerse en el lugar del escritor, ensaya una forma de compromiso propia y por ello va "al hueso" del personaje Walsh. En lugar de colocarse del lado de los críticos y especialistas que abonan la construcción avanzada del personaje canónico, o para decirlo con Braidotti, en lugar de repetir la pose dominante, ella elige la alternativa: posicionarse del lado de Patricia Walsh. En su testimonio, ella argumenta: "Puede ser que lo que tengo que decir sea poco interesante, pero en 
eso yo me identifico con mi propio padre: cuando él busca quién va a dar testimonio en los grandes relatos, elige a las personas que están amenazadas de insignificancia." (MORENO, 2018, p. 301). Es en este sentido, finalmente, que Moreno se pone en "el lugar de Walsh" y efectúa la performance del como si: al intervenir escribiendo en un gran relato, el del horror de la dictadura, y exhumando los testimonios de los sujetos silenciados, que en su caso son las mujeres; más específicamente, al elegir la versión alternativa de Rodolfo Walsh, la de la testigo que propone una diferente al personaje canónico y que está amenazada de insignificancia al igual que las otras mujeres a las que Moreno entrevista.

La disyuntiva ética en la que Walsh se veía involucrado, "la duda entre una causa literaria y una causa periodística —era él quien hacía esas diferencias que luego cuestionaron las lecturas críticas de su obra-” (2018, p. 341), es descartada como tal por Moreno al transferir el compromiso a la materialidad misma de la escritura, o, como lo expresa ella misma, al "poner a mi favor las tipografías, obligarlas a comprometerse" (2018, p. 28). Oración condensa la expresión de su compromiso específicamente en el trabajo con la forma. Cuando la voz narradora observa que al publicar todos los testimonios "completos, quisiera dar cuenta de mis procedimientos de montaje y edición, someterlos a juicios diversos, aunque no simulen una desgrabación pasada en limpio que desestime la escritura como valor en situación, siempre provisional pero jamás neutral” (2018, p. 289), no solo pulveriza la ilusión verosimilizante de un texto con pretensiones realistas, también advierte la importancia de mantener en los testimonios las voces individuales. Es resultado de una elección ética "dejar las palabras del enemigo en cursivas diferenciadas; los testimonios de los sobrevivientes, completos, en un capítulo entero; las citas, casi siempre destinadas al relato oral; las notas, en igual cuerpo que el texto principal y como parte de él." (ídem). Una vez más emerge con claridad la figura de Moreno como archivista: el procedimiento del montaje le permite incluir las voces de las otras bajo la preocupación de realizarlo del modo más directo que el texto le permita. Ese trabajo con la escritura al que se refiere consiste en habilitar espacios de enunciación y coser las partes del patchwork, pero de ninguna manera apropiarse de aquellas voces. No hablar por ellas, sino darles lugar.

\section{La escritura se vuelve inevitable}

A modo de cierre, me gustaría desarrollar una última línea de análisis abierta por aquella disyuntiva entre literatura y periodismo, que en este caso gira en torno al compromiso, y que no es otra cosa más que la discusión sobre qué es la literatura de no-ficción. Para María Sonia Cristoff, "si hay algo que hoy la define, ese algo radica en que lo crucial no son los temas sobre los que se escribe ni tampoco la supremacía técnica con la que se escriba, sino el lugar desde donde se escribe" (2014, p. 12). Ese lugar reviste en cada caso caracteres propios que se delimitan a partir de las "luchas que cada escritor, en la construcción de su poética, entabla con lecturas y precursores y polémicas y apuestas y fantasmas." (ídem). Como ya hemos desarrollado, Moreno coloca el foco de sus lecturas y discusiones en la construcción del personaje de Rodolfo Walsh, y al hacerlo delinea cuál es ese lugar propio, desde donde escribe ella misma.

La escritura en tanto experiencia se presenta desde el comienzo bajo el signo del deseo y las dificultades de llevarla a cabo: "Quise escribir. Pensé que, si no lo hacía, no podría ya escribir otra cosa. Tardé, desistí, volví a intentarlo. Dudé. Hasta que la prórroga que me había dado venció: ya tengo edad para morir." (MORENO, 2018, p. 28). Asumida como un imperativo 
doloroso, la escritura entendida de este modo se abre lugar en un espacio compartido con el cronista a partir de la imposibilidad de resistirle. Desde allí Moreno considera que "la adicción de Walsh es la denuncia, sin que la denuncia pierda su valor al no poder evitarla” (2018, p. 95). Es en esta misma línea que Cristoff afirma que, aun cuando el periodismo y la literatura puedan "leerse como próximas y hasta intercambiables según los contextos" (CRISTOFF, 2014, p. 11), es esta particular experiencia de escribir la que devuelve un sentido al concepto de 'literario': así como afirma que "en Walsh la literatura es, simplemente, lo inevitable” (ídem), según Moreno también es para él aquello a lo que no se puede renunciar (MORENO, 2018, p. 341).

En el caso de Moreno, ¿hay algo a lo que no pueda renunciar? La concreción del proyecto Oración puede leerse como una de esas "aproximaciones amplias a la memoria" que describe Marianne Hirsch en The generation of postmemory (2012): se trata de abordajes de la memoria como problema que no son esencialistas y que se ejercen como prácticas de "lectura reparativa”. A diferencia de otras que confían "en exponer un 'conocimiento verdadero', la 'lectura reparativa' ofrece modos de conocimiento alternativos" (HIRSCH, 2012, p. 24)'. Cuando Moreno se pregunta cómo escuchar las voces de las sobrevivientes a la violencia del Estado, cuál es la verdad que puede obtenerse de allí, la respuesta es claramente a favor de la ficción como construcción. Dado que "La verdad del testimonio es siempre metafórica" (MORENO, 2018, p. 287), la pretensión ingenua de exponer los hechos en sí mismos "no es el hueso factual lo que devela en su sentencia sino una estructura mimética a la judicial en la que la prueba y el documento son accesorios a la retórica fiscal.” (ídem). En esta línea, Moreno como artista archivística asume la responsabilidad de efectuar un modo de justicia mediante la escritura, la construcción y análisis de un archivo en el que el uso de los documentos, muy lejos de ese carácter accesorio, propone una alternativa tanto a "las estructuras hegemónicas de lo estrictamente jurídico" (HIRSCH, 2012, p. 15) como a cualquier forma de justicia poética. La versión moreniana de la escritura como un acto pretende menos transformar directamente las condiciones de aquello que denuncia, que redefinir 'escribir' como verbo performático: ensayar una versión laica de la oración como un avance penoso que se realiza tanto en la experiencia de escritura como en la experiencia de lectura.

\section{Referencias}

AMAR SÁNCHEZ, A. M. El relato de los hechos. Rodolfo Walsh: testimonio y escritura. Rosario: Beatriz Viterbo Editora, 1992.

BERNABÉ, M. Prólogo. En: CRISTOFF, M. S. (comp.) Idea crónica. Literatura de no ficción iberoamericana. Rosario/Buenos Aires: Beatriz Viterbo/Fundación TyPA, 2006.

BERNABÉ, M. Bloody Mary (María Moreno). En:_____. Por otro lado. Ensayos en el límite de la literatura. Toluca de Lerdo: Secretaría de Educación del Gobierno del Estado de México, 2017.

BRAIDOTTI, R. Sujetos nómades. Corporización y diferencia sexual en la teoría feminista contemporánea. Buenos Aires: Paidós, 2000.

CRISTOFF, M. S. Prólogo a la presente edición. La no ficción hoy: una alternativa. En:

\footnotetext{
${ }^{9}$ La traducción es propia.
} 
Falsa calma. Ciudad Autónoma de Buenos Aires: Booket, 2014.

DERRIDA, J. Mal de archivo. Una impresión freudiana. Madrid: Trotta, 1997.

KLEIN, P. Poéticas del archivo: el "giro documental" en la narrativa rioplatense reciente, Cuadernos LIRICO, número 20, 2019. Disponible en: <http://journals.openedition.org/lirico/8605>. Acceso en 4 de abril de 2020.

LUDMER, J. Literaturas postautónomas 2.0. Propuesta Educativa, FLACSO, número 32, pp. 4145, 2009.

MORENO, M. Oración. Carta a Vicki y otras elegías políticas. Ciudad Autónoma de Buenos Aires: Literatura Random House, 2018

FOSTER, H. Un impulso (an)archivístico. En: BERNABÉ, M. (comp.) En el borde del mundo. Vanguardias de archivo en América Latina. Rosario: HyA Ediciones, 2019.

GERBAUDO, A. Por una exhumación responsable (es decir, por una política). En:

Políticas de exhumación: las clases de los críticos en la universidad argentina de la posdictadura, 1984. 1986. Santa Fe: UNL, 2016.

HIRSCH, M. The generation of postmemory. Writing and visual culture after the Holocaust. New York: Columbia University Press, 2012.

Recebido em: 13/05/2020

Aceito em: 02/07/2020 